\title{
Improved lifespan of micro-scale punch tools by ion implantation
}

\author{
Shizuka Nakano, Kuniyoshi Ito*, Tomoyasu Inoue*, Mikiko Yoshida, HisatoOgiso \\ National Institute of Advanced Industrial Science and Technology, Namiki 1-2-1 Tsukuba, Ibaraki 305-8564 \\ Fax: 81-29-861-7091, e-mail: shizuka.nakano@aist.go.jp \\ *SEKI Corporation, Myojincho 2-9-22, Hachioji, Tokyo 192-0046 \\ Fax: 81-42-644-3956, e-mail: sik@seki-corp.co.jp
}

\begin{abstract}
Micro-scale tools, such as punch tools, used in die-forming processes to fabricate micro-scale mechanical devices currently have a relatively short lifespan. The ion implantation method studied in the 1980s shows promise for improving the lifespan of micro punch tools. In this study, $150-\mu \mathrm{m}$-diameter holes were punched in a 0.2 -mm-thick stainless spring steel by using a punch tool. Ion implantation of the punch tool using silicon or gold species decreased the lifespan of the tool. However, the punch tool was then annealed at $700 \mathrm{~K}$ for 30 minutes after ion implantation, the silicon-ion implanted punch tool apparently restored its lifespan to that of an "un-processed" punch tool (no ion-implantation or annealing). Moreover the gold-ion implanted punch tool had a lifespan 10 times longer than an un-processed punch. In conclusion, rearrangement of the disordered lattice caused by ion-implantation damage improves the toughness of micro punch tools.
\end{abstract}

Key words: Die forming, MEMS, punch tool, ion implantation, annealing

\section{INTRODUCTION}

Micro-size devices are demanded by the mobile equipment market. Manufacturers are now answering this demand. For example, the technology of micro electro mechanical systems (MEMS) enables fabrication of micro-size devices. However, MEMS has only been applied to silicon, glass, or certain polymers such as polyimide or polymethyl methacrylate (PMMA). However, the downsizing of devices used in medical, biological, and power supply applications, for example, require a wide variety of materials. Therefore, we previously developed a metal MEMS process that involves die forming [1,2]. Although this process has only been applied to sheet materials, its advantages are low cost, high throughput, and assembly of parts made using the same die. Figure 1 shows the concept of such a total fabrication system.

The lifespan of die tools is a critical problem when the tool size is decreased to the sub-millimeter scale.

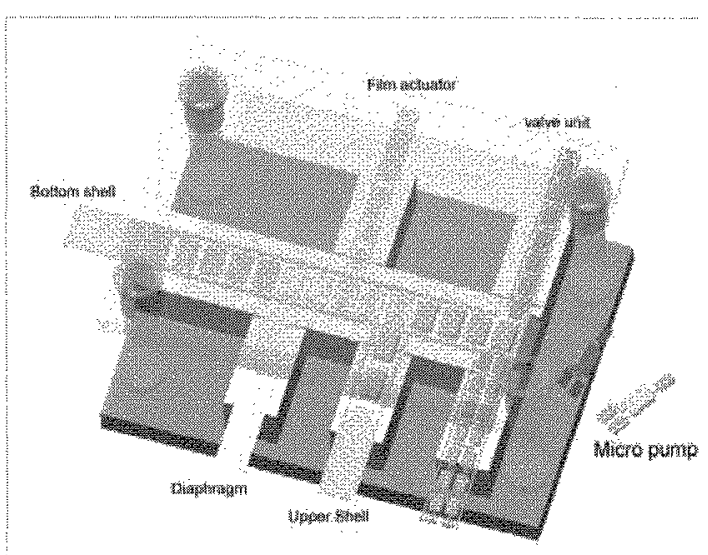

Fig. 1 Concept of a total fabrication system for micro press forming
Because miniaturization degrades the relative machining precision and increases the relative grain size of materials, micro-size die tools, especially, punch tools, become weak. The factor in determinant of its lifespan of micro-punch tools is brittle snap, which is different from of macro punch tools as the chip or round on the edge. To restore these properties, ion implantation technique has been applied to punch tools.

Ion implantation in cobalt-tungsten carbide (Co-WC) for die tools was studied in the 1980's [3-5]. We previously tried nitrogen- and boron-ion implantation of 10-mm-diameter punch tools [6], and found although that their lifespan was increased by a factor of 5 , such tools are inadequate because the ion implantation modified the surface only to a shallow depth and because the fabrication cost was high. However, the effect of surface modification is inversely proportional to the miniaturization of die tools, in this study we reconsidered the effect of ion implantation on improving the lifespan of micro-scale punch tools.

\section{Experimental procedure}

The lifespan of micro punch tools was measured using actual press testing with a precision power press machine and precision die. Figure 2 shows the experimental punch (Fig. 2a), die (2b), and press machine $(2 \mathrm{c})$. The punch was $150 \mu \mathrm{m}$ in diameter, and had a clearance of $7 \%$. The base material was commercial $\mathrm{Co}-\mathrm{WC}$ with a $0.5-\mu \mathrm{m}$ grain size, and the punched material was a $0.2-\mathrm{mm}$-thick stainless spring steel (SUS304CSP-1/2H). These materials were thicker and harder than those typically used in micro-devices, and thus were better for testing the lifespan of micro devices.

Micro punch tools were respectively irradiated with nitrogen $(\mathrm{N})$, carbon $(\mathrm{C})$, aluminum $(\mathrm{Al})$, silicon( $\mathrm{Si})$, iron $(\mathrm{Fe})$, or gold $(\mathrm{Au})$ ion using an ion implanter with a cesium sputter ion source and accelerated at $75 \mathrm{kV}$ at 


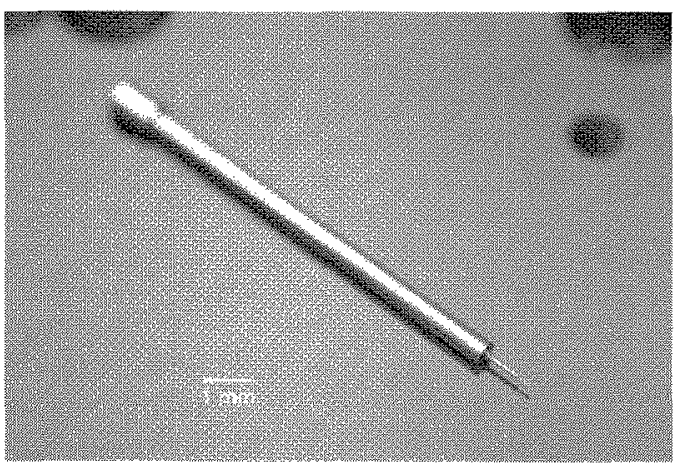

(a)

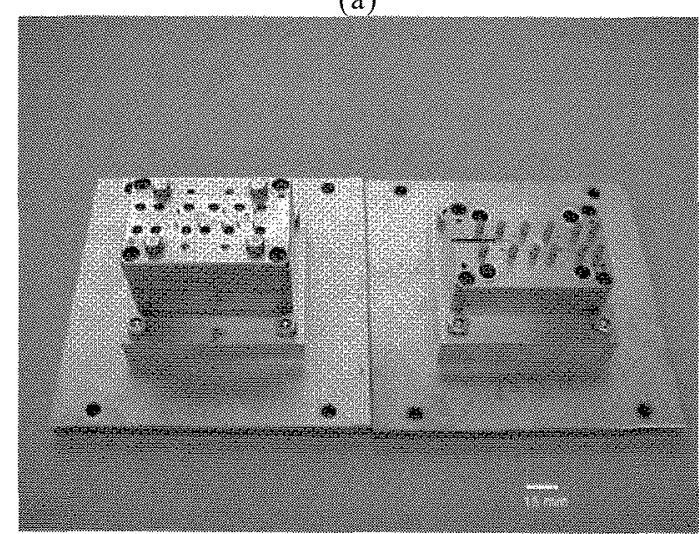

(b)

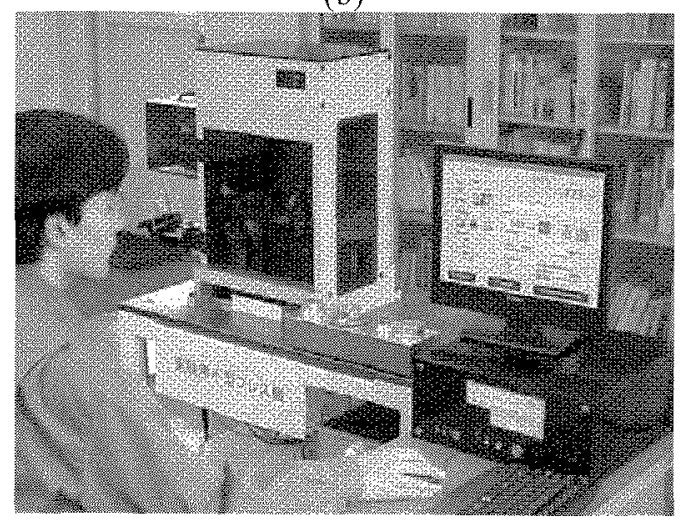

(c)Fig. 2 Photograph of (a) experimental punch, (b) die set, and (c) precision press machine. Total punch length is $33.5 \mathrm{~mm}$,

doses between $1 \times 10^{19}$ and $1 \times 10^{20} \mathrm{~m}^{-2}\left(1 \times 10^{15}\right.$ and $1 \times 10^{16}$ $\mathrm{cm}^{-2}$ ). Each punch tool was subjected to a press test after ion implantation. All of the results were negative, indicating that regardless of ion species, the ion implantation decreased the lifespan of the tool. A possible explanation for this decrease is that the implantation severely damaged the punch surface, as sputtering of $\mathrm{Co}$ binder, elimination of WC grains, softening, and residual stress.

If damage to the tool surface is caused only by lattice disorder, then a post thermal process should restore the tool surface. The silicon- or gold-ion implanted punch tools and also non-implanted punch tools were annealed at $700 \mathrm{~K}$ for 30 minutes. Because compared with other ion species such as $\mathrm{N}, \mathrm{C}, \mathrm{Al}$ or $\mathrm{Fe}$, the $\mathrm{Au}$ or $\mathrm{Si}$ ion implanted punch tools without annealing had a longer lifespan, namely, punched a larger number of holes

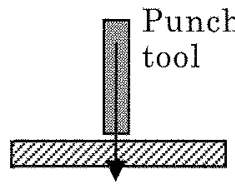

(a)

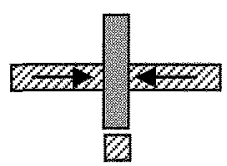

(b)

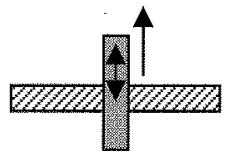

(c)

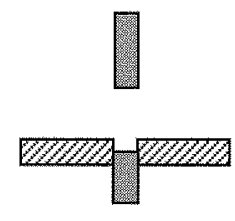

(d)
Fig. 3 Schematic image of fracture mechanism of micro punch tool. (a) Punch a hole in sheet material then compression stress was grown;

(b) punched hole has shrunk by compressive residual stress of sheet; (c) the punch was removed tensile stress was applied to punch tool, a repeat from (a) to (c) has fatigued punch tool; (d) punch tool has snapped.

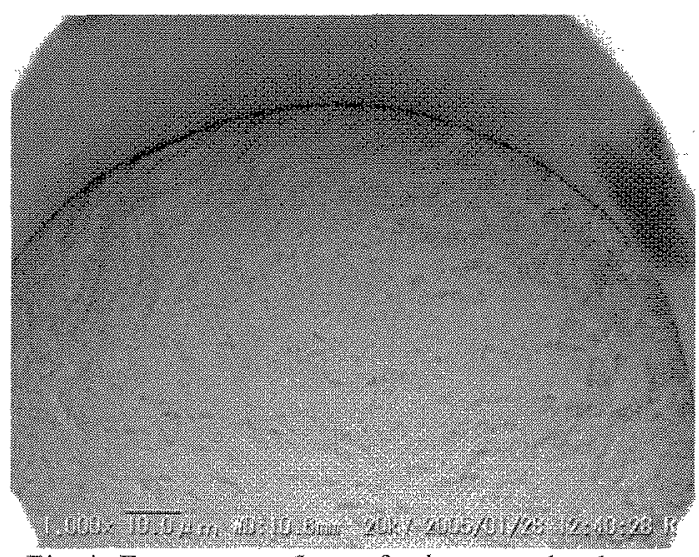

Fig 4. Fracture surface of micropunch, shows brittle broken. Snapped part is squeezed at punched hole.

before wearing out, then we focused these two spices. Results showed that the lifespan of the annealed tools without ion implantation decreased, whereas that of the annealed tools after ion implantation showed no decrease. The punch tools implanted with Au ions at $1 \times 10^{20} \mathrm{~m}^{-2}$ had an average lifespan 10 times or more long than an un-processed punch.

\section{RESULTS and DISCUSSION}

Table 1 summarizes the results of the lifespan tests The numbers shows average lifespan. The comment of "decrease" is a case of all of the tested samples shows smaller than unprocessed average of 420 holes, "decrease / nochange" is decreased average but range is same with unprocessed sample. Although more experimental data is needed for statistical analysis, the 
lifespan of a micro-scale punch tool was increased by $\mathrm{Au}$ ion implantation and annealing at $700 \mathrm{~K}$ for 30 minutes. Because gold is a soft material, $\mathrm{Au}$ ion implantation was not expected to harden the surface of the punch tool. These treatments and conditions were not reported in previous studies, but we consider this annealing at low temperature for a short time was also not expected to have a significant effect. A mechanism of increasing the lifespan has not clear yet, but we explain it as follows.

The irradiated ions collided with $\mathrm{Co}, \mathrm{W}$, and $\mathrm{C}$ atoms, thus creating disorders and defects in the lattice and creating a mixture of Co and WC at the grain boundary. The disorder of WC caused damage, which in turn degraded the toughness of the surface at that particular region. Therefore almost all of ion irradiated punch tools were broken at short lifespan. Residual stress was also considerable. Figure 3 shows the schematic image of fracture mechanism of micro punch tools The micro-punch was broken by tensile stress when the tool was removed from punched hole. This is different from the regular size punch [6] that the life span was determine from a wear of tool edge. The brittle surface was observed on snapped parts (Fig.4). If compressive residual stress remains at the surface of the punch, that region is a weak point during the punching process during repeated compressive and tensile stress. It seems that $\mathrm{Au}$ or $\mathrm{Si}$ ion implantation has affect the residual stress.

The low temperature and short time of the annealing induced order in the atomic lattice by rearranging the $\mathrm{Co}$, $\mathrm{W}$, and $\mathrm{C}$ atoms, and the implanted ions. Cobalt is the only connection among the boundary of.WC grains before ion irradiation and annealing, although it becomes a constituent after the annealing. In WC grains, defects might disappear by recrystallization, which would increase the toughness of the surface. The collision of ions was a non-equilibrium process, which means the disordered atoms were unstable and thus their position in the lattice was easily rearranged by a low temperature, short duration annealing. The heavy gold ions had a stronger affect on the lifespan than did the light silicon ions. The heavier ions generated greater disorder, which had higher potential for rearrangement of the lattice.

Figure 5 shows scanning electron microscope (SEM) images of the surface of fractured punches. Figure 5(a) is an un-processed punch whose lifespan was about 240 holes, and Fig. 5(b) is processed punch whose lifespan was 920 holes. Both punch have damaged parts at the range of about $70 \mu \mathrm{m}$ from fracture part. These areas were grinded by punched material, and processed sample looks like a lower damage. The $75 \mathrm{keV} \mathrm{Au} \mathrm{ion}$ injected only $10 \mathrm{~nm}$, but processed surface get good trybological character. The toughness of the punch tool was therefore restored or increased by suitable lattice rearrangement.

Although these results are preliminary, they reveal a promising direction in the modification of mechanical properties of micro punch tools, namely, introduction of damage by ion irradiation and reconstruction of the damages to improve their successive. $\mathrm{Au}$ ions were effective in increasing the lifespan of a micro punch tool, the toughness of such tools was not adequate for high throughput in the fabrication of micro devices. Further study of other ion species that can extend the lifespan of micro die tools is needed.

Co-WC is not a good material for micro die tools, because it has too many defects. Novel tool materials are expected to be developed, but significant surface modification will be required. The size effect of miniaturization improves the surface of a micro die tool. Further, development of improved micro die tools will require collaborative work involving material, machining, and surface modification for micro machining.

\section{CONCLUSION}

Ion implantation was applied to improve the lifespan of micro punch tools. Au ion implantation and low temperature, short duration annealing tended to increase the lifespan of such tools. This increase probably occurred due to rearrangement of the disordered lattice caused by ion-implantation damage, and this rearrangement improved the toughness of the surface of the tool. Further study of other ion species and characteristics of the modified surface is needed.

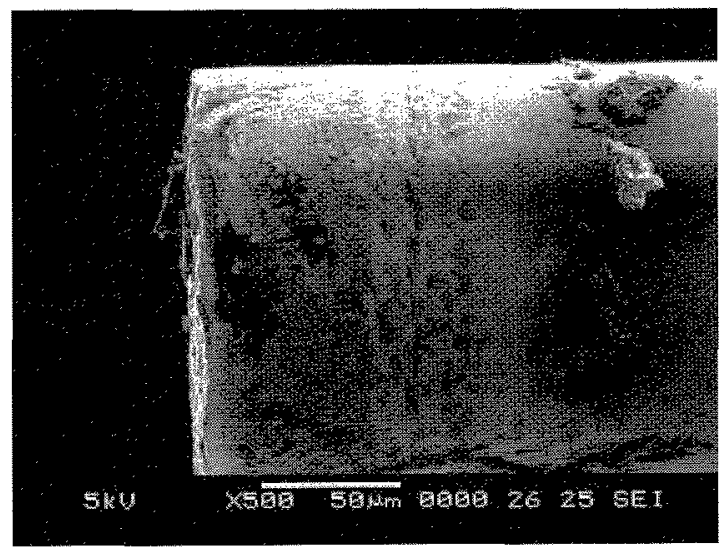

(a)

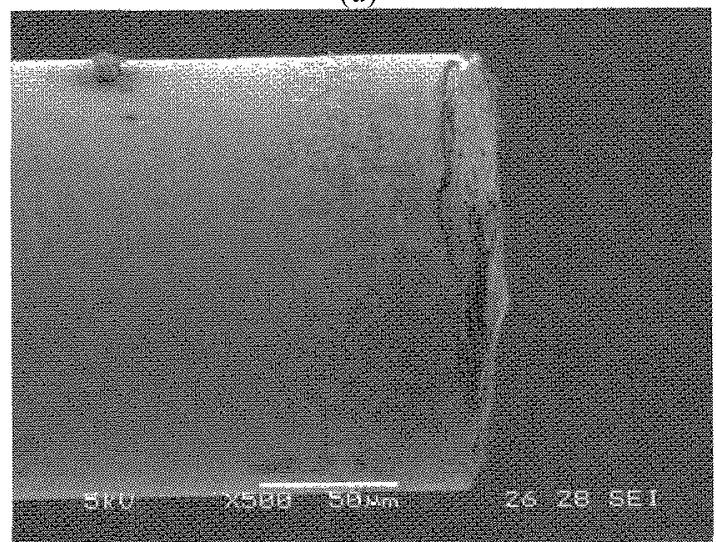

(b)

Fig. 5 SEM image of (a) unprocessed and (b) processed punch after lifespan test. The lifespan of (a) was 240 holes, and that of (b) was 9.20 holes. 
Reference

[1] M.Yang, S.Nakano, K.Manabe, K.Morikawa, K.Ito, H.Saito, K.Fuchigami, T.Yokoi, N.Hotta, Proc. 1st Int. Conf. On New Forming Technology, (2004), Harbin, $135-140$

[2] K.Fujimoto, M.Yang, M.Hotta, H. Koyama, S.Nakano, K.Morikawa, J.Cairney, Journal of Materials Processing Technology, 177, 1-3, (2006), 639-643

[3] A.D.Anderson, M.H.Loretto, G. Dearnaley, Mat. Sci.
Eng. A105/106 (1988) 503-507

[4] J.-P. Hirvonen, J. Koskinen, A. Anttila, D. Stone, C. Paszkiet, Mat. Sci. Eng., 90 (1987) 343-347

[5] Chr. Weist, G. K. Wolf, P. Ballhause, Mat. Sci. Eng. 90 (1987) 399-405

[6] M.Takahashi, S.Nakano, H.Ogiso, T.Sano, S.Fuchizawa, J.Kagami, Proc. 1994 Japanese Spring Conf. for Tech. of Plasticity. (1994) Narahino, 79-82(in Japanese)

Table 1 Average lifespan (expressed in number of holes shown in parentheses) and relative lifespan of ion-implanted and annealed micro punch tools compared with an un-processed punch tool

\begin{tabular}{|c|c|c|c|c|c|c|}
\hline $\begin{array}{c}\text { Ion } \\
\text { dose }\end{array}$ & $\begin{array}{c}\text { Un } \\
\text { processed }\end{array}$ & $\begin{array}{c}\text { Annealing } \\
\text { only } \\
\text { implantation }\end{array}$ & $\begin{array}{c}\text { Si ion } \\
\text { implantation } \\
\text { and annealing }\end{array}$ & $\begin{array}{c}\text { Au ion } \\
\text { implantation }\end{array}$ & $\begin{array}{c}\text { Au ion } \\
\text { implantation } \\
\text { and annealing }\end{array}$ \\
\hline 0 & $(420)$ & $\begin{array}{c}\text { Decrease } \\
(105)\end{array}$ & - & - & - & - \\
\hline $1 \mathrm{E} 15$ & & - & - & - & $\begin{array}{c}\text { Decrease } \\
(90)\end{array}$ & $\begin{array}{c}\text { Decrease/ } \\
\text { No change } \\
(200)\end{array}$ \\
\hline 1 E16 & & - & $\begin{array}{c}\text { Decrease } \\
(160)\end{array}$ & $\begin{array}{c}\text { Decrease/ } \\
\text { No change } \\
(350)\end{array}$ & $\begin{array}{c}\text { Decrease/No } \\
\text { change } \\
(240)\end{array}$ & $\begin{array}{c}\text { Increase } \\
(7095)\end{array}$ \\
\hline
\end{tabular}

